\title{
Slow viruses and chronic disease of the central nervous system
}

\author{
R. N. P. SutToN \\ M.A., D.M., D.Sc., M.R.C.Path., D.C.H. \\ Department of Virology, Withington Hospital, Manchester M20 8LR
}

\begin{abstract}
Summary
Although recognized since the 1930s, slow infections have only recently received considerable attention. There are three types, group A (related to the type C RNA viruses), group B (bizarre agents such as scrapie and kuru) and group $C$ (viruses such as measles which normally produce acute infections but which are behaving here in an unusual fashion). These viruses are only united in that they produce disease with excessively long incubation periods. Many slow infections result in neurological diseases and these will be discussed, together with some possible explanations of their action.
\end{abstract}

\section{Introduction}

Thomas Sydenham, the 'English Hippocrates' of the late seventeenth century, was a man of some wit. On being asked why certain diseases lacked mention in his medical texts, his answer was that he did not write about diseases that he was unable to cure. This reply daunts anyone who writes about viruses, especially those associated with slow infections. Here, not only are we unable to cure but, all too often, we are unable to satisfy the criteria laid down by Robert Koch.

Why then should these slow infections now make a claim for our attention? The roots of this present interest are widely dispersed. Although the transmissibility of scrapie was described in the $1930 \mathrm{~s}$, interest was limited. Until the 1950s, the main stream of animal virology was concerned with the causes of acute disease. In that decade, the bulk of the viruses with which we are now familiar were recognized and handled in the laboratory for the first time. Parallel with these developments came the recognition that viruses could produce malignant transformation in cultured cells and that, in such transformed cells, incomplete viruses and noninfectious viral antigens could be detected.

During the closing years of that decade a veterinary research worker W. J. Hadlow, in a letter to the Lancet in 1959, drew attention to the close resemblance between scrapie and kuru. From this stemmed the flow of original investigation which has now established that some, at least, of the degenerative neurological diseases of man are transmissible.

The term 'slow virus', must not be accepted as one which defines a genuine class. It embraces a number of diverse agents, only united by the chance that they produce diseases with excessively long incubation periods. Nevertheless, with these caveats, the term is of use.

\section{Group A slow infections}

This group includes visna and maedi. The first description of visna was by Sigurdsson, Palsson and Grimsson in 1957. A flock of sheep of Karakul breed was imported into Iceland from Halle in Germany in 1933. Although apparently healthy on arrival, descendants of this flock developed an insidious neurological disease. On some farms, sporadic cases were seen but, on others, a high proportion of the sheep fell ill, with a gradual onset of weakness, usually in the hind legs, which progressed inexorably towards paraplegia or total paralysis and ultimate death; the illness lasting from a few weeks to several months and affecting only animals of 2 years and older. The pathological features were meningeal or subependymal infiltrations and proliferations of cells of the reticuloendothelial system with perivascular cuffing. In advanced cases, there were extensive and widespread lesions which became necrotic; there was secondary demyelination.

Visna virus was recovered by inoculation into healthy sheep and later into tissue cultures of sheep and calf choroid plexus and calf kidney cells (Palsson, 1972). In 1951, the natural disease was eliminated when all the animals in affected flocks were killed; since then the virus has been maintained in the laboratory. It is heat stable, inactivated by light and low $\mathrm{pH}$, stable when frozen and inactivated by fat solvents, formaldehyde and trypsin. There are at least 3 strains which are antigenically related but not identical.

Following infection, virus is found intermittently over many months in cerebro-spinal fluid, blood and saliva. Antibodies develop about 3 months after inoculation and rise to high levels but virus is not eliminated. Visna virus although related to the RNA tumour viruses, is not regularly oncogenic in experimental animals although tumours in mice and in vitro transformation of mouse cells have been recorded. 
Prolonged culture of visna virus in human astrocyte cell culture leads to the production of a modified virus, possibly selected by the cultural conditions, may be a variant or recombinant (McIntyre, Wintersgill and Vatter, 1974).

The demyelination may be a late immune disease, due to antigen-antibody reaction on the surface of infected glial cells or it may be an immunopathological process of the same type as experimental allergic encephalomyelitis.

Maedi was first recognized in 1939 by Gislason in Iceland (Gislason, 1947), with subsequent reports from other countries. It is a slow progressive pneumonia of sheep (never lambs) with insidious onset and high mortality. The lungs are enlarged; histologically, there is scattered periarterial infiltration with lymphocytes and mononuclear cells and, later in the disease, a diffuse mesenchymal proliferation with lymphadenopathy. When visna virus is inoculated into sheep by the intrapulmonary route, maedi-like lesions are produced; and, conversely, lesions in the central nervous system are occasionally seen after infection with maedi virus. This close relationship has been further shown by molecular hybridization studies (Harter et al., 1973) which indicate a relationship with the RNA tumour viruses; and there is an RNA-dependent DNA polymerase (reverse transcriptase) present.

\section{Group B slow infections}

Group B, the subacute spongiform encephalopathies, comprises 4 rare, progressive and fatal neurological conditions, kuru, Creutzfeldt-Jakob disease (CJD), scrapie and transmissible mink encephalopathy (TME). In each, the same neuropathological features are found, vacuolation and degeneration of neurones, an extensive proliferation of astrocytes, gliosis and status spongiosus; these may vary considerably in degree.

Scrapie was known in Europe during the 18th century; in North America and Australia, introduction occurred more recently and, in Iceland, it was first seen during the 1930s. It follows the introduction of infected breeding stock into hitherto scrapie-free flocks. The natural mode of spread is obscure, but the resistence of the agent together with the apparent acquisition of infection from pastures previously grazed by scrapied animals and its experimental oral transmission, suggests spread by ingestion, possibly of fetal membranes at lambing time (Pattison et al., 1972). There is a definite genetic susceptibility.

Scrapie occurs naturally in sheep and, very rarely, in goats and can be induced by inoculation of infected tissue. Incubation periods in goats are less than 1 year and in sheep, from 2 to 5 years, depending upon the breed. The host range exceeds that of kuru or CJD including mice, hamsters, gerbils, rats, voles, mink and a number of primates. The first transmission to primates was by Gibbs and Gajdusek (1972) who induced the disease in a cynomolgous monkey, 5 years after intra-cerebral inoculation of scrapie brain; the appearance of neuronal vacuolation and status spongiosus confirmed the transmission. Five primate species (Cynomolgus, rhesus, capuchin, spider and squirrel monkeys) are susceptible with incubation periods of less than one year to 6 years.

Chandler, in 1961, using scrapied goat brain, was able to infect mice. Here virus is detected 1 week after inoculation into the spleen and, after 4 weeks, in lymph nodes; spread to brain occurs by the sixteenth week and virus remains in high titre throughout the body for the rest of the illness.

Differing strains of scrapie produce different types, distribution and severity of lesions in given strains of mice (Dickinson, 1977). The length of incubation for a given virus strain/mouse breed system is controlled by a single gene - 'sinc' (scrapie incubation). Two alleles are known, $\mathrm{s}^{7}$ (short incubation) and $\mathrm{p}^{7}$ (long incubation); heterozygous mice have intermediate incubation periods. The action of the gene is on the number of host sites available for replication in host tissues. Appropriate manipulation can give rise to an incubation period which is longer than the natural life span of the mouse and thus certain breeds can appear to be genetically immune to infection (Dickinson, Fraser and Outram, 1975).

The other subacute spongiform encephalopathy, TME, closely resembles scrapie. First recognized in 1947 (Barlow, 1972), it occurs sporadically in mink farms and may be an adapted form of scrapie due to the inclusion of infected meat in the mink diet. Scrapie and TME have similar host ranges but whereas scrapie can be transmitted to mink producing a disease indistinguishable from TME, the reverse is not true. Both agents replicate in hamsters but minor differences in clinical features and in pathology indicate the importance of host factors.

Both are sensitive to urea, phenol and periodate but resist formaldehyde, heat, proteolytic enzymes and u.v.-irradiation and doses of X-irradiation which inactivate other viruses. Reports of the size of scrapie vary; filtration experiments indicate 27-47 $\mathrm{nm}$; density gradient plus electron microscopy suggests a size of $14 \mathrm{~nm}$. The agent might be a viroid, an infectious unit composed only of nucleic acid (Diener, 1974). If so, phenol extraction might be expected to yield infective nucleic acid but this is not so and comparison by polyacrylamide gel electrophoresis of RNAs from normal and scrapied mouse brain shows no differences. It is impossible to be certain that the agents contain no nucleic acid and 
the controversy remains unsolved. There is either some other replicating macromolecule (unlikely) or there is close association with cell components which might confer some protection against inactivation. Electron microscopy fails to show any agent. Examination of portions of high infectivity shows small fragments of cell membrane and, using $5^{\prime}$ nucleotidase as a marker, most of the infectivity appears to be in this fraction (Clarke and Millson, 1976). Irregularities in the neuronal membrane suggest that this could be a site where the scrapie agent might be found and it may be that a virus/cell membrane complex could explain the strange physical characteristics of scrapie and TME. The virus or viruses involved could be part-viral genome, undetectable by standard methods.

Kuru was probably observed in the 1920 s but Gajdusek's 1957 report (Gajdusek and Zigas, 1957) was the earliest one to be widely read. Kuru is, or was (the incidence is now declining), endemic in the Fore tribe, an isolated group in the New Guinea Highlands which did not differ from other primitive groups in that cannibalism formed part of its way of life. Transmission of kuru probably took place, either by ingestion or via skin abrasions and the like and, a suggestion influenced by the scrapie/TME link, it is possible that the kuru endemic stemmed from the chance inclusion of Creutzfeldt-Jakob tissue in the menu of the ritual feast.

The first transmission of kuru to chimpanzees was in 1966 (Gajdusek, Gibbs and Alpers, 1966). Intracerebral inoculation of brain tissue produced, after some 20 months, an almost identical disease in the primate. Examination of the brain showed a remarkable similarity, although areas of greatest damage differed, there being a predominant involvement of the cerebral cortex in experimental kuru and of the cerebellum in the naturally occurring disease. Oral transmission has, so far, been unsuccessful.

The incubation period in the chimpanzee ranges from 14 to 39 months, serial transmission reducing this to 11 months. Primary inoculation into New World monkeys has also been successful, resulting in disease with latent periods of 9 months to 3 years but no reduction on serial passage except in marmosets. Transmission from chimpanzees to New World monkeys and primary inoculation of rhesus monkey has also been reported. In all cases, the neuropathology resembled that found in natural kuru.

Interest then focused on Creutzfeldt-Jakob disease, based on neuropathological similarities. This pre-senile dementia occurs sporadically and, occasionally, familially throughout the world. Transmission to the chimpanzee and to a number of primate species, both New and Old World, showed that a pre-senile dementia could be viral in origin. In chimpanzees, the incubation period, 11-14 months, is shorter than for kuru. Unlike kuru, the incubation period is not reduced on serial passage and the disease differs in the appearance of dementia, myoclonus, fasciculations and somnolence. Guinea-pigs (Manuelidis et al., 1976) and mice (Manuelidis, Gorgacz and Manuelidis, 1978) are susceptible and there has been a solitary report that household cats can also be successfully infected (Gajdusek and Gibbs, 1975). Nevertheless, it is now apparent that only some $75 \%$ of patients with Creutzfeldt-Jakob disease harbour agents which are transmissible to primates.

Is Creutzfeldt-Jakob disease transmitted naturally from man to man? Matthews (1975) studied 46 patients over a period of 10 years in Great Britain. There were several geographical clusters where the incidence was significantly higher than the expected $0.09 / 10^{6}$. Matthews suggested that non-fatal cases might remain infective after recovery and, remembering that the incubation period of scrapie in mice can exceed their natural life span, it is also possible that cases remain undetected and die before the onset of disease. The development of CJD has been reported following a corneal graft from an infected donor; the disease also developed in a chimpanzee which was inoculated with brain tissue from the unfortunate transplant recipient. TME virus is found in the corneas of experimentally inoculated animals. A further case, that of a neurosurgeon with suspected CJD raises the question of the infectivity of pathological tissue and the 2 cases where the disease was apparently transmitted by indwelling brain electrodes also bear comment. These few observations have triggered an unfortunate and excessive reaction in many quarters and, in extreme cases, patients with CJD have been refused admission to hospital (Gajdusek et al., 1977) and attempts have been made to prevent experimental work with these agents.

The nature of both agents has been investigated, although much remains obscure. In both kuru and CJD, virus is present in very high titres - greater than $10^{7} \mathrm{ID} / \mathrm{g}$ brain tissue - and kuru has been found in liver, kidney, spleen and mesenteric lymph nodes of infected chimpanzees. CJD has been detected in lymph nodes, liver and kidney.

These agents have not yet been cultured in standard animal or human tissue cultures but it has been shown that both kuru and CJD will persist in explants of infected brain tissue for 11 and 6 months respectively. There are no immune responses and no serological relationship with any known viruses. Particles have not been seen under the electron microscope in kuru but there are unconfirmed reports of papovavirus-like particles in intracellular spaces and in astroglial nuclei in CJD. 
Kuru and CJD are resistant to heat (although 10\% brain homogenates are partially inactivated at $85^{\circ} \mathrm{C}$ for $30 \mathrm{~min}$ ), u.v.-irradiation, lyophilization and storage at $-70^{\circ} \mathrm{C}$. The isolation of CJD from brain tissue kept in $10 \%$ formol saline for 7 months is notable (Gajdusek and Gibbs, 1976).

\section{Group $C$ slow infections}

In group $\mathbf{C}$, subacute sclerosing panencephalitis is characterized by the presence of inclusion bodies in glial and neuronal nuclei, diffuse demyelination and astrocytosis. It affects children and adolescents, occasionally adults. Perhaps one child per million suffers from the disease; the incidence is higher in undeveloped countries and this may be due to an abnormal response to infection with measles in early infancy. The course varies: increasing cerebellar dysfunction, dementia, epilepsy and hypertonia are usual with death supervening after several months. Cases of much shorter course, presenting as an encephalitis with typical subacute sclerosing panencephalitis (SSPE) pathology and those where the condition evolves over a number of years warrant the terms 'acute SSPE' and 'chronic SSPE'.

It is now reasonably well established that SSPE is, at least, associated with measles virus infection. Early observations of paramyxovirus-like nucleocapsids in brain cells were followed by serological studies. These showed elevations of serum and CSF antibodies to measles virus. The titres were higher than those found in measles encephalitis and specific IgM could be detected, consistent with a continuous antigenic stimulus and further evidence of measles, or measles-related virus came from the detection of measles antigen by immunofluorescence.

It seemed that isolation of the agent was to be straightforward. This was not so and the failure of standard methods indicated that the virus might be latent, masked or defective. Successful isolation was only achieved by co-cultivation of trypsinized brain cells with indicator cells and this and the more sophisticated cell fusion techniques have since been repeated. Isolation of infectious virus was not invariable but sometimes the agent was detectable only by the appearance of syncytia and positive immunofluorescence. Similar observations on long term cultures of brain biopsy and post-mortem material showed some variations in the ability to produce infectious virus under these conditions.

The association of measles virus with SSPE is well founded but Koprowski and his group (Barbanti-Brodano et al., 1970; Oyanagi et al., 1970) reported the presence of a second agent in cell cultures. Of 3 cell cultures, each established from brain biopsies, measles virus was isolated by cell fusion from 2 . In the third, measles virus was not detected, but electron microscopy revealed paramyxovirus-like nucleocapsids at early passage levels, superseded later by an accumulation of papovavirus particles. These particles were also seen on electron microscopy of an African green monkey cell line inoculated with both brain cell lines. The absence of papovavirus in non-inoculated cells and the lack of evidence to suggest a source of this virus other than the original brain specimen suggested that SSPE in this case was associated with a dual infection.

The physical properties of the SSPE nucleocapsids resembled those of measles but there were differences in the base sequence. Cross-annealing experiments indicated only $60 \%$ homology between RNA from SSPE-infected cells and RNA from measles infected cells and it appears that whereas all the genetic information of measles virus is contained in SSPE viruses, there is an additional $10 \%$ information in the SSPE genome (Hall and Ter Meulen, 1976).

Animal models have been developed: in adult hamsters, intracerebral inoculation with SSPE virus produces a transient asymptomatic encephalitis; in newborn animals, the disease is fatal; in weanling hamsters, a chronic infection occurs and, of the survivors, some develop an illness with neuropathology similar to SSPE from which the virus can be recovered by co-cultivation.

Progressive multifocal leucoencephalopathy (PML) is a progressive encephalitis of immunologically compromised individuals with multifocal demyelination, astrocytosis and variable, even absent, inflammatory reaction. Papovaviruses of the $\mathrm{SV}_{40}$ /polyoma group are associated with this condition although another virus, JC, has been isolated from at least 20 cases. Like $\mathrm{SV}_{40}$, JC induces tumour formation in newborn hamsters and transforms cells with the production of a $T$ antigen. $\mathrm{JC}$ and its related BK virus are widely prevalent, antibodies being present in $60-70 \%$ of adults.

PML and SSPE are associated with infections by commonly encountered viruses and this has prompted further investigation. Instances of well substantiated viral subacute encephalitis are few. Adenoviruses are sometimes associated with this condition and, in one case, adenovirus type 32 was recovered from brain tissue; 3 or 4 instances of progressive rubella panencephalitis have been described (Townsend et al., 1975). In most of these there were underlying immunological deficiencies, and in others infection may have occurred in utero.

Other animal models have been developed in which subacute encephalitis occurs following viral infection. Zlotnik, Grant and Batter-Hatton (1972) inoculated mice with an avirulent strain of Semliki Forest virus. After 6 weeks, all signs of histological encephalitis had disappeared but when the mice were killed 2 years later, there was astrocytosis, 
spongy degeneration and hydrocephalus. Neurological and intellectual impairment have been described. as late sequelae to infection with Venezuelan equine encephalitis, tick-borne encephalitis viruses and with enteroviruses (Sells, Carpenter and Ray, 1975) but it is difficult to be sure whether these do not result entirely from acute damage to an immature central nervous system (CNS). Considering these unusual late sequelae of infection with conventional viruses, one must remember that latent and apparently harmless infections may occur in asymptomatic individuals. Certainly, such infections are well known in primates where some of the viruses which have been recovered are closely related to the RNA tumour viruses, and a type $\mathrm{C}$ virus recovered from the gibbon brain is related to the GALV-1 strain, itself a candidate human tumour virus. In man, adenovirus type 7 has been recovered from the brain of a patient in whom there was no evidence of encephalitis (Lord, Sutton and Corsellis, 1975) although this adenovirus itself is probably slightly neurotropic (Sutton et al., 1976). We must therefore expect more recoveries of conventional viruses from human brain. However, there is a great lack of suitable control investigations and this inhibits the confidence with which we can attribute any aetiological role to these viruses in the causation of chronic disease.

Multiple sclerosis (MS) is a topic in itself and the only firm fact that should be mentioned is the raised level of antibodies to measles virus in serum and central spinal fluid (CSF).

What factors in host or virus can contribute to the development of a slow infection? In the virus, there are at least 4.

Almost every virus has its temperature-sensitive (TS) mutants which result in a reduction in virulence for the host. Chronic infections have been induced in rodents with TS mutants of measles and reovirus; these infections result in hydrocephalus. These mutants could produce adverse effects in man and their presence in measles vaccines has been linked with a possible increase in numbers of patients with SSPE. There is no evidence of this: nevertheless the possibility remains that viruses of low pathogenicity might be more readily incorporated into the host cell.

The role of defective interfering particles has only recently been recognized. Many instances occur in the laboratory but none in man. Antigenic change is well known in influenza but for this to ensure the preservation of a virus in vivo has only recently become apparent. Equine infectious anaemia virus is excreted in the presence of antibody. This antibody is to the strain of virus present at the time of initial infection, the virus recovered later being antigenically distinct.
In SSPE, the possibility of a dual infection has been suggested. This could be a chance contaminant but hybridization experiments indicate otherwise. Experimentally, $\mathbf{S V}_{40}$ virus does not produce an encephalitis in hamsters, but potentiates the effects of SSPE virus (Yamamoto and Koprowski, 1975).

In rare diseases host factors are important. These may be variations in genetic control; in one instance in mice, there was a linkage through the $\mathrm{H}_{2}$ locus, related to the immune response gene. Another manifestation may be via an increased production of defective interfering virus particles.

In man, genetic influences appear to be important in MS (Leading Article, 1976) and in kuru, and in scrapie these are undoubted. However, in SSPE there is little genetic influence for there have been at least 2 reports of this disease occurring in one only of a pair of identical twins.

Following infection, a virus may be dealt with promptly by the host, but may also become persistent, possibly owing to immunological abnormalities. A further possibility is that infection may result in secondary auto-immune phenomena, for example the development of smooth muscle antibodies in infectious mononucleosis (Sutton et al., 1974).

Kuru was first recognized in the Fore Tribe, one of many in New Guinea, each of which is isolated from its neighbours by geographical features; this isolation is confirmed by linguistic and cultural studies and by analysis of genetic markers such as blood groups. Genetic control plays a part in the development of infection and in an isolated community, stemming from a small initial genetic pool (often tribal lore indicating a single mating as the origin of the tribe) the genetic pattern may favour the expression of disease.

Foci of high incidence of neurological disease have been described in other isolated groups. These include the amyotrophic lateral sclerosis/Parkinsonism/dementia complex on the island of Guam, amyotrophic lateral sclerosis in the Kii peninsula, Japan, and other motor neurone disease in New Guinea. Investigation of these foci will provide pointers to the aetiology of these conditions as found sporadically elsewhere.

These isolated populations are not entirely in exotic areas. The Amish are found in New England; the inhabitants of many Caribbean islands are derived from remarkably small initial populations; in rural England there are still villages where one or two surnames are shared amongst a few hundred individuals and close inter-breeding occurs and in several of our large cities (e.g. Manchester) there are closely knit Orthodox Jewish communities. Here, epidemiological surveys might well provide fruitful.

Of the common neurological diseases, MS has probably moved from the 'possible' to the 'probable' 
category. A condition which is, at present only a 'possible' is senile dementia.

More than one in 10 of those older than 65 years are demented and in England and Wales there are about 650000 . Excluding physical disturbances to the cerebral blood flow, a substantial proportion remains, labelled as senile dementia. The characteristic pathological features of this condition, plaques and neurofibrillary tangles, are scattered widely and are found in most elderly people. How are they associated with dementia?

It seems likely that, as in the cerebellum (Eccles, 1973), the neurones are arranged in some kind of three-dimensional lattice, with a vast excess of neurones, necessary to ensure reliable computation of the neurological inflow and outflow. Minor neuronal damage at strategic points could interfere with the accuracy of computation; conversely, substantial damage at non-strategic areas would be non-effective. The location of strategic points is not known, hence the difficulty in equating histological damage with the clinical effects of impaired computation, whether this be dementia or an interference in thought process. Of potential triggers for these pathological lesions, slow virus infections are reasonable candidates.

There is no evidence for group A viruses in man, other than a general feeling that oncornaviruses are probably present in human tissues.

In group B one is on firmer ground. Kuru and CJD are accepted and similar agents have been recovered from patients with familial Alzheimer's disease and with familial neurological diseases. There is speculation that all these agents are related.

Viruses in group $\mathbf{C}$ are more susceptible to investigation. However, evidence for the role of such viruses in man, with important exceptions, is slight. Although viruses of many kinds have been recovered from the brains of apparently healthy primates, little is known about the situation in man.

In summary, 2 points may be made. Firstly, some neurological conditions, hitherto regarded as degenerative or heredo familial are now known to be associated with identifiable agents. This association removes a mental block which has hitherto hindered investigation. Secondly, these viruses have been categorized in various groups. This may be misleading for between these viruses there are close resemblances as well as dissimilarities.

\section{References}

Barbanti-Brodano, G., Oyanagi, S., Katz, M. \& KoprowsKI, H. (1970) Presence of two different viral agents in brain cells of patients with SSPE. Proceedings of the Society for Experimental Biology and Medicine, 134, 230.

BARLOW, R.M. (1972) Transmissible mink encephalopathy: pathogenesis and nature of the aetiological agent. Journa ${ }_{l}$ of Clinical Pathology, 25: Supplement (Royal College of Pathologists) No. 6, 102.

Chandler, R.L. (1961) Encephalopathy in mice produced with scrapie brain material. Lancet, $i, 1378$.

Clarke, M.C. \& Millson, G.S. (1976) The membrane $\overrightarrow{\bar{F}}$ location of scrapie infectivity. Journal of General Virology, $\stackrel{\oplus}{+}$ $31,441$.

Dickinson, A.G. (1977) The pathogenesis of scrapie in $\bar{\sigma}$ inbred mice. In: Slow Virus Infections (Ed. by Ter Muelen, $\bar{c}$ V. \& Katz, M.), p. 3. Springer Verlag, Berlin.

Dickinson, A.G., Fraser, H. \& Outram, G.W. (1975) Scrapie incubation time can exceed natural lifespan. Nature. London, 256, 732.

DIENER, T.O. (1974) Viroids: the smallest known agents of $\vec{\circ}$ infectious disease. Annual Review of Microbiology, 28, 23. -

ECCLES, J.L. (1973) The cerebellum as a computer: patterns $\vec{\omega}$ in space and time. Journal of Physiology, 229, 1.

GaJDUSEK, D.C. \& GibBS, C.J. (1975) Familial and sporadic chronic neurological degenerative disorders transmitted $\frac{O}{3}$ from man to primate. Advances in Neurology, 10, 291.

GAJDUSEK, D.C. \& GiBBS, C.J. (1976) Survival of Creutzfeldt- $\circlearrowleft$ Jakob disease in formol-fixed brain tissue. New England क Journal of Medicine, 294, 553.

GaJdusek, D.C., Gibbs, C.J. \& AlPers, M. (1966) Experi-.? mental transmission of kuru-like syndrome to chimpan- $\vec{A}$ zees. Nature. London, 209, 974.

Gasdusek, D.C., Gibbs, C.J., Asher, D.M., Brown, P., 음 Diwan, A., Hoffman, P., Nemo, G., Rohwer, R. \&White, L. (1977) Precautions in medical care of, and in 7 handling materials from, patients with transmissible virus $\mathbb{D}$ dementia (Creutzfeldt-Jakob disease). New England Journal of Medicine, 297, 1253.

GaJDUSEK, D.C. \& Zigas, V. (1957) Degenerative diseases off the central nervous system in New Guinea. New Engla Journal of Medicine, 257, 974.

GiBBS, C.J. \& GAJDuSEK, D.C. (1972) Transmission of scrapie to the cynomolgus monkey (Macaca fascicularts Nature, New Biology, 236, 73.

Gislason, G. (1947) Pattur um rannsoknir a vegum saudfjarsjukdoma-nefndar [Studies on sheep disease]. Iceland $\bar{\partial}$ Ministry of Agriculture Publications, pp. 235-254. (Quoted by Palsson, 1972).

Hadlow, W.J. (1959) Scrapie and kuru. Lancet, ii, 289.

Hall, W.W. \& TER Muelen, V. (1976) RNA homology $\overrightarrow{\vec{\Omega}}$ between subacute sclerosing panencephalitis and measles $\frac{\rho}{3}$ viruses. Nature. London, 264, 474.

Harter, D.H., AXel, R., BurNy, A., Gulati, S., Schlom, J. \& SPIEgElman, S. (1973) The relationship of visna, Maedi and RNA tumour viruses as studied by molecular hybridization. Virology, 52, 287.

LEADING ARTICLE (1976) Histocompatibility antigens and multiple sclerosis. Lancet, ii, 1286.

LORD, M.A., Sutron, R.N.P., \& CoRsellis, J.A.N. (1975) Recovery of adenovirus type 7 from human brain cell $\delta$ cultures. Journal of Neurology, Neurosurgery and $引$ Psychiatry, 38, 710.

MCINTYRe, E.H., Wintersgill, C.J. \& VATTER, A.E. (1974) Prolonged culture of visna virus in human astrocytes. Beitraege zur Pathologie (Stuttgart), 152, 163.

Manuelidis, E.E., GorgaCZ, E.J. \& MaNuElidis, L. (1978) Transmission of Creutzfeldt-Jakob disease with scrapie- $\odot$ like syndromes in mice. Nature. London, 271, 778.

Manuelidis, E.E.. Kim, J., ANGelo, J.N. \& Manuelidis, L. 응 (1976) Serial propagation of Creutzfeldt-Jakob disease in $\mathrm{\omega}$ guinea-pigs. Proceedings of the National Academy of Sciences of the United States of America, 73, 223.

Matrhews, W.B. (1975) Epidemiology of Creutzfeldt-Jakob disease in England and Wales. Journal of Neurology, \& Neurosurgery and Psychiatry, 38, 210.

Oyanagi, S., Ter Muelen, V., Muller, D., Katz, M. \& T KOPROWSKI, H. (1970) Electron microscopic observations 
on SSPE brain cell cultures, their correlation with cytochemical and immunological findings. Journal of Virology, 6, 370.

PALsSon, P.A. (1972) Maedi-visna. Journal of Clinical Pathology, 25: Supplement (Royal College of Pathologists) No. 6, 115.

Pattison, I.M., Hoare, M.N., Jebbett, J.N. \& Millson, G.C. (1972) Spread of scrapie to sheep and goats by oral dosing with foetal membranes from scrapie-affected sheep. Veterinary Record, 90, 465.

Sells, C.J., Carpenter, R.L. \& Ray, C.G. (1975) Sequelae of central nervous system enterovirus infections. New England Journal of Medicine, 292, 1.

Sigurdsson, B., Palsson, P.A. \& Grimsson, H. (1957) Visna: a depnyelinating transmissible disease of sheep. Journal of Neuropathology and Experimental Neurology, 16, 389.

Sutton, R.N.P., Emond, R.T.D., Thomas, D.B. \& Doniach,
D. (1974) The occurrence of autoantibodies in infectious mononucleosis. Clinical and Experimental Immunolog. $17,427$.

Sutton, R.N.P., Pullen, H.J.M., Blackledge, P., Brown, E.H., Sinclair, L. \& SwIFT, P.N. (1976) Adenovirus type 7: 1971-1974. Lancet, ii, 987.

TOWNSEND, J.J., BARINGer, J.R., Wolinsky, J.S., MALamUd, N., Mednick, J.P., PANITCh, H.S., SCOTt, R.A.T., Oshiro, L.S. \& Cremer, N.E. (1975) Progressive rubella panencephalitis: late onset after congenital rubella. New England Journal of Medicine, 292, 990.

Yamamoto, T. \& Koprowski, H. (1975) A study of the influence of papovirus upon encephalitis caused by SSPE agent. Acta neuropathologica. Berlin, 21, 159.

ZlotNIK, I., GRANT, D.P. \& BatTer-HatTon, D: (1972) Encephalopathy in mice following inapparent Semliki Forest virus (SFV) infection. British Journal of Experimental Pathology, 53, 125. 